\title{
Pengaruh Konsentrasi Gliserol dalam Pengencer Tris Terhadap Kualitas Spermatozoa Kambing Sapera Before Freezing
}

\section{Effect of Glycerol Concentration in Tris Diluents on Spermatozoa Quality of Sapera Goats Before Freezing}

\author{
Novi Fitria Hanifah ${ }^{1 *}$, Hermin Ratnani², Muhammad Thohawi Elziyad Purnama ${ }^{3}$, \\ Tjuk Imam Restiadi ${ }^{2}$, Bodhi Agustono ${ }^{4}$, Ragil Angga Prastiya ${ }^{2}$ \\ ${ }^{1}$ Mahasiswa, ${ }^{2}$ Departemen Reproduksi Veteriner, ${ }^{3}$ Departemen Anatomi Veteriner, ${ }^{4}$ Departemen Peternakan, \\ Fakultas Kedokteran Hewan, Universitas Airlangga \\ Kampus C Mulyorejo, Surabaya, Jawa Timur, Indonesia 60115 \\ *Corresponding author: novi.fitria.hanifah-2016@ fkh.unair.ac.id
}

\begin{abstract}
Abstrak
Penelitian ini bertujuan untuk menentukan konsentrasi gliserol yang optimal dalam pengencer tris dalam mempertahankan kualitas spermatozoa kambing Sapera. Penelitian ini menggunakan kambing Sapera jantan umur 1.5 tahun. Konsentrasi gliserol yang digunakan adalah 5\%, 6\% dan 7\%. Semen ditampung dua kali dalam seminggu dengan menggunakan vagina buatan. Hasil penelitian menunjukkan rata-rata persentase motilitas dan viabilitas spermatozoa pada pengencer dengan gliserol 6\% masing-masing $62.33 \%$ dan $75.83 \%$ terdapat perbedaan yang signifikan $(\mathrm{p}<0.05)$ dibandingkan pada pengencer dengan gliserol $5 \%$ masing-masing $57.67 \%$ dan $68.33 \%$ dan $7 \%$ masing-masing $59 \%$ dan $70.33 \%$. Rata-rata abnormalitas pada pengencer dengan gliserol 5\%, 6\% dan 7\% masing-masing 8\%, 7.5\% dan $7.67 \%$ tidak terdapat perbedaan yang signifikan ( $>0.05)$. Dapat disimpulkan bahwa penambahan gliserol 6\% dalam pengencer Tris berhasil melindungi spermatozoa dari cekaman dingin selama proses gliserolisasi, sehingga dapat mempertahankan motilitas, vibilitas dan abnormalitas spermatozoa.
\end{abstract}

Kata kunci: before freezing, gliserol, kambing Sapera, kualitas spermatozoa

\begin{abstract}
This study aimed to determine the optimal glycerol concentration in the tris dilution to maintain the spermatozoa quality of Sapera goats. This study used 1.5 year old male Sapera goats. The glycerol concentration used 5\%, 6\% and 7\%. Semen was collected twice a week using an artificial vagina. The results showed the average percentage of motility and viability of spermatozoa in diluents with glycerol $6 \%$ was $62.33 \%$ and $75.83 \%$, respectively; there were significant differences $(p<0.05)$ compared to diluents with glycerol $5 \%$ was $57.67 \%$ and $68.33 \%$, respectively; and $7 \%$ was $59 \%$ and $70.33 \%$, respectively. Average abnormalities in diluents with glycerol 5\%, 6\% and 7\% were $8 \%, 7.5 \%$ and $7.67 \%$, respectively; there were no significant differences ( $p>0.05)$. It can be concluded that the addition of $6 \%$ glycerol in Tris diluents succeeded in protecting spermatozoa from cold stress during the glycerolization process, so as to maintain the motility, viability and abnormalities of spermatozoa.
\end{abstract}

Keywords: before freezing, glycerol, Sapera goat, quality of spermatozoa

Received: 11 Februari 2020

Revised: 25 Maret 2020

Accepted: 18 April 2020

\section{PENDAHULUAN}

Susu kambing merupakan salah satu penopang susu nasional meski tidak sebanyak produksi susu sapi. Menurut Sutama dan Budiarsana (2017), tiga diantara kambing perah yang dapat menghasilkan susu di Indonesia antara lain Peranakan Etawa (PE), Saanen dan persilangan Saanen dengan Peranakan Etawa (Sapera). Kambing Sapera memiliki produktivitas dengan rata-rata dua liter/hari (Deviana et al., 2018). Konsumsi susu kambing diharapkan mampu mencukupi kebutuhan susu di Indonesia. Badan Pusat Statistik (2018) mengatakan bahwa populasi kambing di Indonesia pada tahun 2018 sebanyak 18.720 .706 
ekor, namun data statistik kambing perah masih belum diketahui pasti. Peningkatan populasi kambing perah mutlak diperlukan dalam upaya meningkatkan produktivitas susu kambing.

Inseminasi buatan merupakan teknologi alternatif yang saat ini banyak digunakan untuk meningkatkan produktivitas dan populasi ternak. Kualitas semen merupakan salah satu hal yang sangat mempengaruhi keberhasilan pada inseminasi buatan. Kualitas semen yang tidak segera digunakan pasca penampungan akan mengalami penurunan. Kualitas semen dapat dipertahankan pada saat penyimpanan dan pembekuan dengan cara penambahan bahan pengencer yang dapat mendukung kelangsungan hidup spermatozoa. Pengencer yang baik mampu mempertahankan kualitas semen (Hikmawan dkk., 2016).

Titik beku cairan pada semen dapat diturunkan dengan menambahkan gliserol ke dalam semen dan cairan pengencer. Fungsi lain dari penambahan gliserol ke dalam cairan pengencer dan semen yaitu dapat mencegah terbentuknya kristal es dan menghindari terjadinya cekaman dingin (cold shock). Penekanan proses metabolisme spermatozoa dapat dilakukan dengan cara menurunkan suhu, proses tersebut juga mudah dipulihkan kembali dengan cara mengembalikannya pada suhu normal (Hardijanto dkk., 2010).

Menurut Tambing dkk. (2000), gliserolisasi merupakan proses penting dalam penyimpanan semen. Gliserol dalam pengencer dengan konsentrasi yang optimal dapat melindungi spermatozoa secara efektif. Begitupun sebaliknya, apabila konsentrasi gliserol tidak optimal maka dapat menimbulkan penurunan kualitas pada spermatozoa. Pada penelitian sebelumnya oleh Tambing dkk. (2000) menyatakan bahwa penambahan gliserol dengan konsentrasi 6\% pada kambing Peranakan Etawa dapat mempertahankan kualitas spermatozoa dengan rata-rata presentase motilitas spermatozoa $62.29 \%$. Penelitian oleh Islamiati dkk. (2016) pada kambing Peranakan Etawa dengan penambahan gliserol $6 \%$ menunjukkan rataan motilitas spermatozoa sebanyak $58.66 \%$. Sampai saat ini belum diketahui konsentrasi gliserol yang tepat pada kambing Sapera. Tujuan penelitian ini untuk mengetahui pengaruh konsentrasi gliserol dalam pengencer tris terhadap kualitas spermatozoa kambing Sapera.

\section{METODE PENELITIAN}

\section{Alat dan Bahan}

Bahan yang digunakan dalam penelitian ini yaitu semen yang ditampung dari seekor kambing Sapera yang berumur 1.5 tahun, penampungan semen menggunakan vagina buatan dilakukan 2 kali dalam satu minggu. Bahan yang digunakan dalam penelitian ini baik pemeriksaan makroskopis maupun mikroskopis yaitu $\mathrm{NaCl}$ fisiologis $0.9 \%$, Eosin-Negrosin, bahan pengencer dari BBIB Singosari (gliserol, tris, kuning telur, asam sitrat, fruktosa, penicillin dan streptomycin), vaselin, aquades, dan air hangat. Alat yang digunakan antara lain vagina buatan (IMV), tabung berskala (penampung semen), refrigerator $\left(\right.$ Sharp $\left.^{\circledR}\right)$, tabung reaksi (Iwaki $\left.{ }^{\circledR}\right)$, mikropipet $\left(\right.$ Socorex $\left.^{\circledR}\right)$ ukuran 100, microtube, mikroskop binokular (Olympus ${ }^{\circledR}$ ), mikroskop trinokular (Nikon Eclips E200 ${ }^{\circledR}$ ) dengan Software NiS Element 4.40, Spektrofotometer (Thermo scientific Genesys $20^{\circledR}$ ), obyek glass dan cover glass $\left(\right.$ OneMed $\left.^{\circledR}\right)$.

\section{Perlakuan}

Penelitian ini merupakan penelitian eksperimental dengan menggunakan metode Rancangan Acak Lengkap (RAL). Penelitian ini menggunakan 3 buah perlakuan dengan konsentrasi gliserol yang berbeda dan 6 ulangan. Perlakuan satu (P1) penambahan gliserol 5\%, perlakuan dua $(\mathrm{P} 2)$ penambahan gliserol $6 \%$ dan perlakuan tiga (P3) penambahan gliserol $7 \%$.

Pemeriksaan motilitas pada spermatozoa dilakukan dengan cara meneteskan spermatozoa sebanyak satu tetes pada obyek glass, kemudian tutup menggunakan cover glass dan lakukan pengamatan di bawah mikroskop dengan perbesaran $100 \times$ atau $400 \times$ untuk melihat adanya gerakan maju pada spermatozoa. Hitung dan beri nilai dari jumlah keseluruhan spermatozoa yang diamati dalam persen (\%) (Susilowati dkk., 2010). 
Pemeriksaan viabilitas pada spermatozoa dengan menggunakan perwarnaan EosinNigrosin akan mewarnai kepala spermatozoa yang mati karena lapisan lipid pada spermatozoa telah rusak, sedangkan pada spermatozoa yang masih hidup tidak akan terwarnai atau transparan. Pemeriksaan dilakukan dengan cara meneteskan zat warna dan semen masing-masing sebanyak satu tetes pada obyek glass, lalu campurkan keduanya sampai homogen, kemudian ulas dan keringkan preparat di atas nyala api, lakukan pengamatan dibawah mikroskop. Spermatozoa yang diamati dinyatakan dalam persen (\%). Waktu yang digunakan dalam melakukan penghitungan persentase spermatoza maksimal adalah 15 detik (Susilowati dkk., 2010).

Pemeriksaan abnormalitas pada spermatozoa menggunakan preparat ulas yang telah dibuat menggunakan pewarnaan Eosin-Nigrosin, kemudian dilakukan pengamatan dibawah mikroskop dengan perbesaran $100 x$ atau 400x. Hitung berapa spermatozoa yang abnormal dan jumlah dari spermatozoa lalu dinyatakan dalam persen (\%) (Susilowati dkk., 2010).

\section{Analisis Data}

Data dianalisis menggunakan analisis statistika dengan uji One Way Analysis of Variance (ANOVA). Jika terdapat perbedaan yang signifikan $(\mathrm{p}<0.05)$, maka dilanjutkan Uji Duncan.

\section{HASIL DAN PEMBAHASAN}

Evaluasi semen segar kambing Sapera dilakukan untuk mengetahui kelayakan semen tersebut dapat dilanjutkan dalam proses selanjutnya atau tidak. Hasil evaluasi semen setelah perlakuan yang diamati adalah motilitas, viabilitas dan abnormalitas yang dapat dilihat dalam Tabel 1.

Berdasarkan analisis statistik rata-rata persentase motilitas terdapat perbedaan yang signifikan $(\mathrm{p}<0.05)$ antara G5 $(57.67 \%)$ dan G6 (62.33\%), G5 (57.67\%) dan G6 (62.33\%) tidak terdapat perbedaan yang signifikan $(\mathrm{p}>0.05)$ terhadap G7 (59.00\%) (Tabel 2). Menurut
Khrisnamurti (2005) persentase motilitas spermatozoa merupakan salah satu patokan paling sederhana dalam penelitian semen untuk inseminasi buatan. Motilitas merupakan kemampuan gerak spermatozoa yang dijadikan sebagai ukuran kesanggupan spermatozoa untuk membuahi sel telur. Gliserol dapat mencegah kerusakan spermatozoa pada proses pembekuan (Anggarsari, 2015). Menurut Mumu (2009) gliserol akan memasuki siklus perombakan fruktosa pada triosa fosfat dan selanjutnya akan dirombak menjadi asam laktat, fruktosa yang tersedia ini akan menyebabkan spermatozoa tetap bergerak, fruktosa berperan dalam menghasilkan energi berupa ATP yang mengandung fosfat anorganik yang kaya energi.

Analisis statistik rataan persentase viabilitas menunjukkan bahwa G5 (68.33\%) terdapat perbedaan yang signifikan $(\mathrm{p}<0.05)$ terhadap G6 (75.83\%), antara G5 (68.33\%) dengan G7 $(70.33 \%)$ tidak terdapat perbedaan yang signifikan ( $p>0.05)$, sedangkan G6 (75.83\%) dengan G7 (70.33\%) terdapat perbedaan yang signifikan $(\mathrm{p}<0.05)$ (Tabel 2). Spermatozoa yang hidup tidak dapat menyerap zat warna EosinNegrosin, sedangkan spermatozoa yang mati akan menyerap zat warna Eosin-Negrosin karena permeabilitasnya menjadi meningkat setelah sel tersebut mati (Layla dan Aminah, 2002). Kematian spermatozoa disebabkan oleh rusaknya membran plasma, kerusakan membran plasma ini akan mengganggu proses fisiologis maupun metabolisme spermatozoa (Azzahra dkk., 2016). Penambahan gliserol dalam pengencer tris akan dapat menyeimbangkan konsentrasi intraseluler dan ekstraseluler karena gliserol masuk dalam membran plasma. Spermatozoa akan mengalami eksoosmosis dimana spermatozoa yang terpapar gliserol akan terjadi pengeluaran cairan dari dalam sel, kemudian terjadi pengkerutan sel dan gliserol berdifusi kedalam sel spermatozoa sehingga ukurannya menjadi normal (Tambing, 2000).

Hasil analisis rataan persentase abnormalitas antara G5 (8.00\%), G6 (7.50\%) dan G7 (7.67\%) tidak terdapat perbedaan signifikan $(\mathrm{p}<0.05)$ (Tabel 2). Abnormalitas yang diamati dalam penelitian ini hanya abnormalitas sekunder saja. 
Tabel 1. Hasil pemeriksaan semen segar kambing Sapera

\begin{tabular}{lc}
\hline Parameter & Rata-rata \\
\hline Volume (ml) & $0.98 \pm 0.18$ \\
Warna & Krem \\
Bau & Khas Prengus \\
Konsistensi & Kental \\
Konsentrasi (juta/ml) & $3628.50 \pm 373.36$ \\
pH & $6.67 \pm 0.52$ \\
Gerakan Massa & +++ \\
Gerakan Individu (\%) & $82.33 \pm 2.25$ \\
Viabilitas (\%) & $85.83 \pm 3.76$ \\
\hline
\end{tabular}

Tabel 2. Evaluasi spermatozoa kambing Sapera setelah perlakuan

\begin{tabular}{cccc}
\hline \multirow{2}{*}{ Parameter } & \multicolumn{3}{c}{ Gliserol (\%) } \\
\cline { 2 - 4 } & G5 & G6 & G7 \\
\hline Motilitas & $57.67 \pm 2.94^{\mathrm{a}}$ & $62.33 \pm 4.72^{\mathrm{b}}$ & $59.00 \pm 2.37^{\mathrm{ab}}$ \\
Viabilitas & $68.33 \pm 5.89^{\mathrm{a}}$ & $75.83 \pm 2.32^{\mathrm{b}}$ & $70.33 \pm 2.73^{\mathrm{a}}$ \\
Abnormalitas & $8.00 \pm 0.89^{\mathrm{a}}$ & $7.50 \pm 1.05^{\mathrm{a}}$ & $7.67 \pm 1.03^{\mathrm{a}}$ \\
\hline
\end{tabular}

a,b superskrip berbeda pada baris yang sama menunjukkan perbedaan yang signifikan $(p<0.05)$

Abnormalitas yang ditemukan dalam penelitian ini yaitu kepala tanpa ekor, ekor terputus, ekor kusut dan ekor melingkar. Menurut Arifiantini dkk. (2006) abnormalitas sekunder dapat disebabkan karena kesalahan dalam preparasi maupun ejakulasi. Suyadi dkk. (2012) menambahkan bahwa peningkatan persentase abnormalitas juga dapat disebabkan oleh adanya perokdasi lipid. Perokdasi lipid merupakan kerusakan membran yang terjadi akibat adanya reaksi antara asam lemak tak jenuh dan radikal bebas. Menurut Wilandari dkk. (2013) perokdasi lipid dapat menyebabkan kerusakan pada membran plasma spermatozoa.

Gliserol dapat meminimalisir terjadinya kerusakan membran plasma akibat perokdasi lipid yaitu dengan cara mengikat gugus fosfolipid (Parks dan Graham, 1992; Saputro et al., 2018). Kemampuan gliserol dalam meminimaisir kerusakan membran tersebut dapat mengurangi peningkatan abnormalitas. Menurut Mumu (2009) gliserol akan memasuki siklus perombakan fruktosa pada triosa fosfat dan selanjutnya akan dirombak menjadi asam laktat, fruktosa yang tersedia ini akan menyebabkan spermatozoa tetap bergerak, fruktosa berperan dalam menghasilkan energi berupa ATP yang mengandung fosfat anorganik yang kaya energi.

\section{KESIMPULAN}

Dapat disimpulkan bahwa penambahan gliserol dengan konsentrasi 6\% dalam pengencer tris memiliki rata-rata motilitas $62.33 \pm 4.72$, viabilitas $75.83 \pm 2.32$ dan abnormalitas $7.50 \pm$ 1.05. Konsentrasi gliserol $6 \%$ mampu melindungi spermatozoa dari cekaman dingin selama proses gliserolisasi, sehingga dapat mempertahankan motilitas, viabilitas dan abnormalitas spermatozoa.

\section{UCAPAN TERIMA KASIH}

Peneliti mengucapkan terimakasih kepada PSDKU Universitas Airlangga di Banyuwangi dan Bumi Kesilir Farm yang telah memberikan kesempatan bagi peneliti untuk dapat melangsungkan penelitian dan memperoleh data.

\section{DAFTAR PUSTAKA}

Anggarsari, W.T. 2015. Status Kondisi Prestasi Program Inseminasi Buatan pada Sapi Perah Hasil Inseminasi Buatan di Dataran Tinggi dan Dataran Rendah di Wilayah Kerja Kutt Suka Makmur Grati [Skripsi]. Fakultas Kedokteran Hewan. Universitas Airlangga. 
Arifiantini, R.I., Yusuf, T.L., Mulyadi, Y. 2006. Efektifitas waktu pemaparan gliserol terhadap motilitas spermatozoa pada pembekuan semen domba lokal menggunakan pengencer tris kuning telur. Bogor Agricultural University. Bogor.

Azzahra, F.Y., Setiatin, E.T., Samsudewa, D. 2016. Evaluasi Motilitas dan Persentase Hidup Semen Segar Sapi PO Kebumen Pejantan Muda. Jurnal Sain Peternakan Indonesia, 11(2), 99-107.

Badan Pusat Statistik. 2018. Populasi Kambing Menurut provinsi, 2009-2018. https://www.bps.go.id/dynamictable/2015/12 /17/1022/populasi-kambing-menurutprovinsi-2009-2018.html. $\quad[18$ September 2019].

Deviana, D., Cahyo, N.P.D., Kumalaningrum, D.R., Kusuma, W.A., Lailiyah, F., Purnama, M.T.E. 2018. Rekayasa Konsentrat Bekatul dengan Tepung Jantung Pisang Dapat Meningkatkan Berat Badan dan Menurunkan Kadar Kolesterol Kambing. Jurnal Sain Veteriner, 36(1), 74-79.

Hardijanto., Susilowati, S., Hernawati, T., Sardjito, T., Suprayogi, T.W. 2010. Buku Ajar Inseminasi Buatan. Fakultas Kedokteran Hewan. Universitas Airlangga. Hal: 39-40.

Hikmawan, S.W., Ciptadi, G., Wahyuni, S. 2016. Kualitas Spermatozoa Swim Up Kambing Peranakan Etawah Hasil Pembekuan Menggunakan Metode Vitrifikasi Dengan Persentase Gliserol Yang Berbeda. J. Ternak Tropika, 17(1), 42-48.

Islamiati, M.U, Darodjah, R.S., Soeparna.2016. Pengaruh Level Gliserol dalam Pengencer Tris-Sitrat Kuning Telur terhadap Motilitas dan Abnormalitas Sperma Kambing Peranakan Etawah Post Thawing. Fakultas Peternakan Universitas Padjadjaran. Hal: 5.
Khrisnamurti, D. 2005. Persentase Motilitas Progresif dan Persentase Hidup Spermatozoa Post Thawing Hasil Paparan Sinar Ultraviolet (UV) [Skripsi]. Fakultas Kedokteran Hewan. Universitas Airlangga. Hal: 32.

Layla, Z., Aminah, S. 2002. Uji Kualitas Sperma dan Penghitungan Jumlah Pengencer dalam Upaya Menentukan Keberhasilan Inseminasi Buatan. Temu Teknis Fungsional Non Peneliti. Balai Penelitian Ternak. Bogor.

Mumu, M.I. 2009. Viabilitas Semen Sapi Simental Yang Dibekukan Menggunakan Krioprotektan Gliserol. J. Agroland, 16(2), 172-179.

Parks, J.E., Graham, J.K. 1992. Effects of Cryopreservation Procedures on Sperm Membranes. Theriogenol., 38, 209-222.

Saputro, A.L., Hamid, I.S., Prastiya, R.A., Purnama, M.T.E. 2018. Hidroponik Fodder Jagung sebagai Substitusi Hijauan Pakan Ternak Ditinjau dari Produktivitas Susu Kambing Sapera. Jurnal Medik Veteriner, $1(2), 48-51$.

Susilowati, S., Hardijanto, Suprayogi, T.W., Sardjito, T., Hernawati, T. 2010. Penuntun Pratikum Inseminasi Buatan. Pusat Penerbitan dan Percetakan Unair (AUP). Surabaya. Hal: 14-21.

Sutama, I.K., Budiarsana, I.G.M. 2017. Kupas Tuntas Beternak Kambing. Jakarta Timur: Penebar Swadaya. Hal: 143-144.

Suyadi, A., Rachmawati, N., Iswanto. 2012. Pengaruh $\alpha$-Tocopherol yang Berbeda dalam Pengencer Dasar Tris Aminomethanekuning Telur Terhadap Kualitas Semen Kambing Boer yang Disimpan pada Suhu 50C. Jurnal Ilmiah Ilmu-ilmu Peternakan, 22(3), 1-8. 
Tambing, S.N., Toelihere, M.R., Yusuf, T.L., Sutama, I. 2000. Pengaruh gliserol dalam pengencer Tris terhadap kualitas semen beku kambing Peranakan Etawah. JITV, 5(2), 1-8.

Wilandari, T.D., Abdul, A., Ibrahim, M. 2013. Pengaruh Pemberian Ekstrak Sarang Semut
(Myrmecodia pendens Merr \& Perry) Terhadap Morfologi Spermatozoa Tikus Putih (Rattus norvegicus L) yang Dipapar Asap Rokok. Universitas Negeri Gorontalo. 